\title{
El fenómeno de los periodistas ciudadanos en los conflictos armados actuales
}

\section{The Phenomenon of Citizen Journalists in Contemporary Armed Conflicts}

\author{
Chema Suárez Serrano ${ }^{1}$ \\ Doctor en Derecho Internacional Público
}

Recibido: 05-03-16

Aprobado: 27-06-16

\section{Resumen}

Muchas veces, las noticias difundidas por los llamados periodistas ciudadanos logran un enorme impacto en la opinión pública, hasta el punto de que las grandes empresas informativas ayudan a su difusión, especialmente en los conflictos armados. El auge de este fenómeno se debe a las facilidades que brindan las nuevas tecnologías digitales a los usuarios no especializados, que con sólo un teléfono con conexión a Internet gozan de un acceso inusitado tanto a la emisión como a la recepción de mensajes a escala mundial. Los tribunales de justicia han comenzado a otorgar a los ciudadanos la misma protección que a los profesionales, cuando se trata de la defensa del derecho a la libertad de expresión, y las Organizaciones Internacionales ya equiparan a ambos en derechos y obligaciones. Las nuevas tecnologías no sólo han cambiado el perfil de los conflictos armados; también obligan a replantearse quién es periodista, qué es el periodismo.

Palabras-clave: Conflicto armado, información, Internet, libertad de expresión, medios de comunicación, periodismo ciudadano.

\footnotetext{
${ }^{1}$ (chemasuarez1@gmail.com). Doctor en Derecho Internacional Público y Relaciones Internacionales por la Universidad de Granada (España) y Máster en Relaciones Internacionales. Licenciado en Periodismo, trabaja en Radio Televisión de Andalucía (España). Otras publicaciones: "El Papel de Las Naciones Unidas en la Guerra de Irak. Análisis de las resoluciones sobre Irak desde la invasión de Kuwait en 1990, y la actuación del Consejo de Seguridad ante la guerra de marzo de 2003". Revista Contra Relatos desde el sur, $\mathrm{n}^{\circ}$ 4, Centro de Estudios Avanzados de la Universidad Nacional de Córdoba, Argentina, 2007. "Los medios de comunicación ante los prisioneros de guerra ¿perjudican o protegen cuando difunden sus imágenes? El caso de Muammar Gaddafi”. Revista Contra Relatos desde el sur, $\mathrm{n}^{\circ}$ 9; 2012, Centro de Estudios Avanzados de la Universidad Nacional de Córdoba, Argentina.
} 


\begin{abstract}
News published by so-called citizen journalists increasingly create such an impact on public opinion, that media companies take them as valid sources of information, especially in armed conflicts. The rise of this phenomenon derives from the easy access to new digital technologies on the part of non-specialist users, who only need a phone with Internet access to reach a worldwide audience. The courts of justice have started to grant citizens the same protection as journalists, when it comes to defending the right to freedom of expression, and international organizations equate both professionals and non-professionals in terms of rights and obligations. New technologies have not only changed the profile of armed conflict; they have also forced us to rethink who is a journalist, and indeed what journalism is.
\end{abstract}

Key-words: Armed conflict, citizen journalism, freedom of expression, information, Internet, media.

\begin{abstract}
"Los periodistas ciudadanos contribuyen a crear una mayor diversidad de criterios y opiniones, e incluso a proporcionar información sobre sus comunidades y sobre grupos que precisan una atención particular, como las mujeres, los pueblos indígenas y las minorías. Además, desempeñan una función crítica de vigilancia en los países donde no hay libertad de prensa. Lo que es más importante aún, pueden proporcionar una visión inmediata e interna de un conflicto o una catástrofe, mientras que los periodistas profesionales no siempre obtienen acceso al escenario de las hostilidades, o pueden tener que viajar durante días para llegar a un lugar o a una zona de desastre"2.
\end{abstract}

\title{
1. La irrupción del periodismo ciudadano
}

Probablemente el periodismo ciudadano, no profesional, ha contado tantas noticias relevantes en los últimos años como los reporteros más experimentados, especialmente en situaciones de conflicto. En ocasiones el improvisado informador estaba en el lugar por pura coincidencia y se convirtió en testigo excepcional fruto del azar; pero en muchas otras acudió voluntariamente en busca de la noticia y logró difundirla incluso anticipándose a los profesionales que trabajan para las grandes empresas de comunicación.

\footnotetext{
${ }^{2}$ Informe del Relator Especial de la ONU sobre la promoción y protección del derecho a la libertad de opinión y expresión, Frank La Rue. 11 agosto 2010. A/65/284. Párrafo 63.

http://www.acnur.org/t3/fileadmin/Documentos/BDL/2011/7497.pdf?view=1
} 
En un caso o en otro, algunas de las imágenes más destacadas de este siglo han sido captadas por ciudadanos anónimos con sus teléfonos móviles, cámaras de vídeo o fotografía, para difundirlas por Internet y luego a través de los principales medios de comunicación, que no dudan en publicarlas conscientes de su valor informativo ${ }^{3}$. Y no sólo las cabeceras de noticias, también la $\mathrm{UNESCO}^{4}$ ha reconocido el valor de estas aportaciones por ofrecer una mayor diversidad de fuentes de información y aumentar la oferta de noticias al alcance de cualquier persona.

Este fenómeno se llama periodismo ciudadano, (citizen journalism, en inglés) pero también periodismo público, participativo, democrático, callejero... y las personas que lo practican son conocidas como periodistas ciudadanos, o incluso netizens, por la simbiosis que se produce entre los usuarios e Internet, la principal herramienta para la publicación de sus mensajes. En realidad no existe una definición universal para referirse a este proceso, pero por lo general se entiende que se trata de un periodismo independiente, a menudo realizado por aficionados desde el escenario de un acontecimiento, y difundido a nivel mundial por medios modernos, (mediante sitios de intercambio de fotos, vídeos, blogs, microblogs, foros en línea, tableros de anuncios electrónicos, redes sociales, podcasts y otros) $)^{5}$.

Todo está ocurriendo de manera muy reciente, podemos decir que aún estamos asistiendo a sus primeros pasos, si bien hay sonoros antecedentes dignos de mención: el asesinato del presidente norteamericano John Fitzgerald Kennedy el 22 de noviembre de 1963 lo grabó un vecino de Dallas, Abraham Zapruder, con la cámara doméstica que había comprado días antes. Sus imágenes recogieron el magnicidio de manera fortuita y son las únicas que captaron el atentado en su totalidad, en apenas 18 segundos. Zapruder no era periodista, ni profesional de la imagen, ni miembro de las fuerzas de seguridad, pero su cinta sirvió a la investigación policial y judicial posterior, fue emitida por las televisiones en todo el mundo y pronto se convirtió en la película doméstica más difundida de la historia.

Por lo tanto, periodistas ciudadanos ha habido siempre, pero este fenómeno a escala global, con capacidad de impacto superior en muchas ocasiones a las grandes empresas de comunicación y cuyos efectos pueden

\footnotetext{
${ }^{3}$ Las primeras imágenes que vimos sobre los atentados de París en noviembre de 2015, y Bruselas en marzo de 2016 fueron tomadas por las propias víctimas y testigos directos, usando los teléfonos móviles y difundiéndolas inmediatamente por Internet. Otro hecho similar con enorme impacto mediático fueron los atentados del 11 de septiembre de 2001 en Nueva York. El ataque del primer avión contra las Torres Gemelas fue recogido por Jules Naudet, quien filmaba la intervención de un equipo de bomberos que supervisaba un escape de gas en la zona. Durante su grabación sucedió el primer impacto, que él recogió de manera fortuita. Hoy, su cámara se expone en el American History Museum de Washington.

${ }^{4}$ UNESCO, Tendencias Mundiales en Libertad de Expresión y Desarrollo de los Medios (2014). Accesible en: http://unesdoc.unesco.org/images/0022/002297/229704S.pdf

${ }^{5}$ Informe del Relator Especial de la ONU sobre la promoción y protección del derecho a la libertad de opinión y expresión, op. cit. nota 2, párr. 62.
} 
sacudir la opinión pública mundial en apenas unos segundos, está recién nacido y en plena evolución. Su despegue se debe a las facilidades que brindan las nuevas tecnologías de la información y comunicación a los usuarios anónimos, no especializados, proporcionándoles un acceso sin precedentes a los medios de comunicación, y en consecuencia, ofreciendo nuevas vías para informar ${ }^{6}$.

En efecto, la Unión Internacional de las Telecomunicaciones (ITU) revela cómo el número de usuarios de telefonía móvil con conexión a Internet en todo el mundo se ha multiplicado por 12 entre 2007 y 2015 como término medio $^{7}$. Un asombroso incremento que resulta aún más llamativo en los países en desarrollo, que en este mismo período han multiplicado por 55 las líneas móviles con banda ancha. Las consecuencias de este colosal aumento de ciudadanos con acceso a Internet móvil aún están por ver, ya que esta es la zona del mundo donde la libertad de expresión -amén de otros derechos- se vulnera con más facilidad y donde los gobiernos ejercen un control directo en el tráfico de información vía Internet ${ }^{8}$. Desde luego, la llamada primavera árabe, a la que enseguida me referiré, probablemente no habría sido posible sin esta previa expansión de las herramientas digitales entre la población.

La práctica del Consejo de Europa nos da una idea de la importancia que ha ido cobrando este fenómeno, que en sólo cuatro años pasó de ignorar a los ciudadanos informadores, a darles cabida. En 1996, ni siquiera se refiere a ellos cuando acota el término "periodista":

"For the purposes of this recommendation, the term "journalist" must be understood as covering all representatives of the media, namely all those engaged in the collection, processing and dissemination of news and information including cameramen and photographers, as well as support staff such as drivers and interpreters".

Y en 2000 amplía el cupo para considerar periodista a quien ejerza tal actividad, sin la precisión de la Recomendación anterior, dejando abierto el campo a los periodistas ciudadanos:

6 Ibíd.

${ }^{7}$ En 2007 había en todo el mundo 268 millones de líneas activas de móviles con banda ancha; mientras que en 2015 ascienden a 3.459. En los países en desarrollo pasaron de 43 a 2.368 millones en el mismo período, lo que significa que la población con conexión a internet en el teléfono móvil en las zonas menos desarrolladas pasó en este tiempo del 0,8 al 39,1 por ciento. Fuente: International Telecommunication Union. Key ICT indicators for developed and developing countries and the world, totals and penetration rates (2015) http://www.itu.int/en/ITU-D/Statistics/Pages/stat/default.aspx

${ }^{8}$ Reporters Without Borders, World press freedom index 2015 http://index.rsf.org/\#!/

${ }_{9}$ Recommendation No. R (96) 4 of the Committee of Ministers to Members States on the Protection of Journalists in situation of Conflicts and Tensions (Adopted by the Committee of Ministers on 3 May 1996 at its $98^{\text {th }}$ Session)

http://www.coe.int/t/dghl/standardsetting/media/doc/cm/rec(1996)004_EN.asp

Araucaria. Revista Iberoamericana de Filosofía, Política y Humanidades, año 18, nº 36. Segundo semestre de 2016. Pp. 111-130. ISSN 1575-6823 e-ISSN 2340-2199 doi: 10.12795/araucaria.2016.i36.06 


\begin{abstract}
"The term journalist means any natural or legal person who is regularly or professionally engaged in the collection and dissemination of information to the public via any means of mass communication" $"$.
\end{abstract}

Pero el verdadero punto de inflexión aparece a partir de 2010. Desde entonces, instituciones como la Asamblea General de la ONU, la UNESCO y las propias asociaciones profesionales, comienzan a ocuparse del fenómeno de los periodistas ciudadanos. La práctica totalidad de las instituciones que se han pronunciado sobre este asunto coinciden en que es a partir del cambio de siglo y especialmente en esta segunda década, cuando su efecto se generaliza principalmente en dos frentes. El primero radica en el ejercicio mismo de la libertad de expresión, que se ha beneficiado de un impulso sin precedentes, a la vez que se enfrenta a los mismos ataques para cercenarlo. Y en segundo lugar, en la modificación de la práctica del periodismo como disciplina. Las nuevas herramientas digitales han clausurado el esquema convencional según el cual la información fluye desde arriba (los periodistas) hacia abajo (los consumidores), porque las posibilidades comunicativas entre los particulares se han ampliado hasta el punto de revertir el proceso.

Hoy día, las organizaciones de periodistas reconocen sin ambages la importancia de este fenómeno, al que miran como un sector emergente de informadores no profesionales, pero sometido a las mismas amenazas que quienes lo son. Prueba de que lo consideran un hecho consolidado es la elaboración de los prestigiosos informes anuales de la ONG Reporteros Sin Fronteras ${ }^{11}$ que desde 2011 incluye a los periodistas ciudadanos en sus estadísticas sobre siniestralidad, y desde 2013 se ocupa de ellos en sus listas sobre encarcelados o detenidos por informar. Del mismo modo, el Comité para la Protección de los Periodistas (CPJ por sus siglas en inglés) ${ }^{12}$ denuncia el acoso contra los ciudadanos desde 2012 , por el mero hecho de informar. En el último lustro han muerto 150 periodistas no profesionales y netizens; y el año 2015 se cerró con al menos 164 ciudadanos presos por emitir información u opiniones, superando los 149 profesionales encarcelados $^{13}$. Además, desde 2012, Internet es el canal de mayor riesgo, pues los periodistas asesinados por publicar en este canal - profesionales o no-superan a quienes trabajaban en los medios convencionales (prensa, radio o televisión) ${ }^{14}$.

${ }^{10}$ Recommendation No. R (2000) 7 of the Committee of Ministers to Members States on the Right of Journalists not to disclosure their sources of information (Adopted by the Committee of Ministers on 8 March 2000, at the 701st meeting pf the Ministers' Deputies) http://www.coe.int/t/dghl/ standardsetting/media/doc/cm/rec(2000)007\&expmem_EN.asp

${ }^{11}$ Reporters Without Borders,

http://en.rsf.org/press-freedom-barometer-journalists-killed.html?annee=2011

12 Committee to Protect Journalists, http://www.cpj.org/security/2012/05/dont-get-your-sourcesin-syria-killed.php

${ }^{13}$ Reporters Without Borders,

http://en.rsf.org/press-freedom-barometer-netizens-imprisoned.html?annee=2015

${ }^{14}$ Committee to Protect Journalists, https://cpj.org/killed/2015/ 


\section{2. ¿Quién es periodista? ¿Qué es periodismo?}

Una de las primeras consecuencias de la revolución tecnológica es la imposibilidad de responder de manera cierta y definitiva a estas preguntas: ¿quién es hoy periodista? ¿qué es el periodismo? La Asamblea General de la ONU señala que el periodismo está en constante evolución, ya que actualmente abarca desde las aportaciones de los medios de comunicación convencionales hasta las de personas particulares que buscan, reciben y difunden todo tipo de información e ideas ${ }^{15}$, lo cual indica la dificultad de acotar su significado estricto. Pese a todo aún quedan mínimos inamovibles, como el marco que definió el Tribunal Europeo de Derechos Humanos (TEDH), cuando se refiere a los periodistas y a los medios de comunicación como vigilantes (public watchdogs) necesarios para la democracia ${ }^{16}$ (si bien la era tecnológica en la que estamos inmersos prueba que ya no son los únicos guardianes, inaugurando una nueva categoría de personas vigilantes). La Justicia Internacional Penal también abre la puerta a los ciudadanos periodistas cuando el Tribunal para la ex Yugoslavia (TPIY) define genéricamente a los corresponsales de guerra como individuos que informan desde las zonas de conflictos ${ }^{17}$. Puede entenderse, a estos efectos, que un civil no profesional también sería periodista cuando emite mensajes de elaboración propia sobre la evolución del conflicto, o sobre operaciones puntuales.

De manera que, aunque alguna vez pudo llegar a ser facultad exclusiva, informar ya no es sólo asunto de profesionales. De hecho, la información, es uno de los pilares de la libertad de expresión, recogida en el artículo 19 de la Declaración Universal de los Derechos Humanos y del en Pacto Internacional de Derechos Civiles y Políticos, que necesita al menos dos agentes para su desarrollo: las personas que lo ejercitan, y los canales a través de los cuales pueden hacerlo. Entre las primeras es obvio que se incluyen los periodistas profesionales, pero también desde tiempo reciente los ciudadanos anónimos, mientras que entre las vías para ejercerlo no sólo hay que contar con los medios de comunicación convencionales, puesto que Internet se ha impuesto como herramienta principal, dando cabida a los usuarios particulares. De hecho, el TEDH prefiere usar términos como "el informador" o "el comunicador", y no sólo "el periodista" en su jurisprudencia sobre el artículo 10 del Convenio Europeo de Derechos Humanos, incluso cuando hay implicado un profesional ${ }^{18}$.

\footnotetext{
15 A/RES/68/163 (21 de febrero de 2014) http://www.un.org/en/ga/search/view_doc. asp?symbol=A/RES/68/163\&referer=http://www.un.org/en/events/journalists/\&Lang=S

16 ECHR, Case of Goodwin v. The United Kingdom. 27 march 1997. http://hudoc.echr.coe.int/ sites/eng/pages/search.aspx?i=001-57974

17 ICTY, Decision on prosecution's second request for a subponea of Jonathan Randal. 29 junio 2003, par. 10. http://www.icty.org/x/cases/brdanin/tdec/en/030630.htm

18 Bustos Gilbert, R., "Los derechos de libre comunicación en una sociedad democrática" en VV.AA, La Europa de los derechos. El convenio europeo de Derechos Humanos. Madrid, Centro de Estudios Políticos y Constitucionales, 2014, pp.473-509.
} 
El Comité de Derechos Humanos de la ONU suele usar la expresión "función periodística", que incluye a profesionales y particulares:

"En la función periodística, participan una amplia variedad de personas, como analistas y reporteros profesionales y de dedicación exclusiva, autores de blogs y otros que publican por su propia cuenta en medios de prensa, en Internet o por otros medios" 19 .

Así las cosas, cualquier persona puede convertirse en informador $\mathrm{y}$, llegado el caso, recurrir a las instituciones judiciales correspondientes para reclamar protección ante una violación de los derechos relacionados con la comunicación $^{20}$. La labor del periodista supone básicamente buscar, recibir y difundir información, pero los tribunales exigirán que quien realice esa función se involucre en la defensa de la libertad de expresión ${ }^{21}$. El TEDH establece que una de las primeras obligaciones del periodista es confirmar la veracidad de la información ${ }^{22}$ y se refiere, además, al periodista responsable como condición para merecer la protección que concede el artículo 10 del Convenio Europeo de Derechos Humanos. Le reclama una responsabilidad social, es decir, un compromiso con los ciudadanos para hacerles llegar sólo mensajes limpios, exentos de intencionalidad y sensacionalismo, con el único propósito de informar con buena fe:

\begin{abstract}
"While enjoying the protection afforded by the Convention, journalists must, when exercising their duties, abide by the principles of responsible journalism, namely to act in good faith, provide accurate and reliable information, objectively reflect the opinions of those involved in a public debate, and refrain from pure sensationalism"23.
\end{abstract}

En cierto modo, el TEDH recoge el pálpito de los grandes maestros de este oficio como Kapuscinski, que ya apeló a la buena fe una década antes:

${ }^{19} \mathrm{CCPR} / \mathrm{C} / \mathrm{GC} / 34$ Comité de Derechos Humanos de la ONU, Observación General número 34 (12 de septiembre de 2011), párr. 44. http://www.un.org/es/comun/docs/index.asp?symbol=CCPR/C/ GC/34\&referer=http:/ /www.un.org/es/ga/documents/symbol.shtml\&Lang=E

${ }^{20}$ El Derecho a la Libertad de Expresión también aparece recogido en el artículo 10 del Convenio Europeo de Derechos Humanos (1950), artículo 19 del Pacto Internacional de Derechos Civiles y Políticos (1966) o en el 13 de la Convención Americana de Derechos Humanos (1969). La Constitución Española (1978) lo contempla en el artículo 20, dentro del Titulo 1, que goza del nivel más alto de protección. N. del A.

21 Sentencia Corte Interamericana de Derechos Humanos (CIHD). Caso Mémoli Vs. Argentina. Excepciones Preliminares, Fondo, Reparaciones y Costas. 22 de agosto de 2013. Serie C No. 265 (párr.120) http://www.corteidh.or.cr/docs/casos/articulos/seriec_265_esp.pdf

${ }_{22}$ European Court of Human Rights, Judgment Bladet Tromso and Stensaas v. Norway, 20 May 1999, (para. 55). http://hudoc.echr.coe.int/eng\#\{“fulltext”:[“Fressoz"],”appno":[“21980/93”],"item id":[“001-58369"] $\}$

${ }^{23}$ European Court of Human Rights, Judgment Novaya Gazeta v. Rusia, 28 march 2013 (para. 37) http://hudoc.echr.coe.int/sites/eng/pages/search.aspx?i=001-117683 
"Para ser periodista hay que ser, ante todo, buena persona. Mediante la empatía, se puede comprender el carácter del propio interlocutor y compartir de forma natural y sincera el destino y los problemas de los demás"24.

Al igual que TEDH, la jurisprudencia Americana exige al periodista veracidad y buena fe, como ya ha refrendado la Suprema Corte de Justicia de México $^{25}$. Son requisitos universalmente reconocidos y elementales para gozar del amparo que dispensa el artículo 13 de la Convención Interamericana de Derechos Humanos, ya que la veracidad no es sólo garantía para la salvaguarda de los derechos de los protagonistas de la noticia, sino también del derecho que tenemos todos los ciudadanos sin distinción a recibir una versión no distorsionada de la realidad. ${ }^{26}$ Los informadores que así actúen podrán ampararse en la protección judicial, sin importar que sean profesionales o no, lo hagan como trabajo remunerado o sin remunerar, dispongan o no de titulación académica o acreditación oficial.

¿Y qué es periodismo? La Corte Interamericana de Derechos Humanos (CIDH) nos ofrece un muy útil enfoque, al definirlo como la manifestación primaria de la libertad de expresión ${ }^{27}$. Su principal función debe ser el ejercicio y la defensa de ese derecho mediante la puesta en práctica de la comunicación social. Según esta pauta periodismo es, básicamente, la acción encaminada a la defensa de la libertad de expresión. ¿Importa que sean profesionales o ciudadanos quienes actúen? La jurisprudencia internacional no parece tener este aspecto demasiado en cuenta, como tampoco la necesidad de una titulación o formación específica:

"El periodismo no puede concebirse meramente como la prestación de un servicio al público a través de la aplicación de los conocimientos o la capacitación adquiridos en la universidad. Al contrario, los periodistas, en razón de la actividad que ejercen, se dedican profesionalmente a la comunicación social" 28 .

Y entre los medios para ejercer la libertad de expresión Internet se ha convertido en el canal principal al tiempo que ha facilitado la incorporación definitiva de los ciudadanos a la actividad de informar, de hacer periodismo. El

\footnotetext{
${ }^{24}$ Kapuscinski, R., Los cínicos no sirven para este oficio: Sobre el buen periodismo, Barcelona, Ed. Anagrama, 2007, p. 38.

25 Suprema Corte de Justicia de la Nación. México, Septiembre 2012. http://www.bjdh.org.mx/ interamericano/doc_JP_CADH?documento=2001677.pdf

${ }^{26}$ Sentencia CIDH. Caso Kimel Vs. Argentina. 2 de mayo de 2008, párr. 79.

http://www.corteidh.or.cr/docs/casos/articulos/seriec_177_esp.pdf

27 Sentencia CIDH Caso Herrera Ulloa c. Costa Rica. 2 julio 2004, párr. 117 y 118. http://www. corteidh.or.cr/docs/casos/articulos/seriec_107_esp.pdf

28 Sentencia CIDH Caso Herrera Üllō c. Costa Rica, 2 de julio de 2004, párr. 118. http://www.corteidh.or.cr/docs/casos/articulos/seriec_107_esp.pdf
} 
Tribunal Supremo de los Estados Unidos reconoce que Internet ha difuminado las diferencias entre profesionales o usuarios convencionales, y ambos deben ser considerados iguales a la hora de exigirles responsabilidades o de otorgarles protección para el ejercicio de la libertad de expresión:

"With the advent of the Internet and the decline of print and broadcast media, moreover, the line between the media and others who wish to comment on political and social issues becomes far more blurred"29.

Las herramientas digitales han eliminado la línea divisoria entre ciudadanos y profesionales, por lo que discriminar jurídicamente el trabajo de unos u otros sería contrario a la Primera Enmienda a la Constitución de los Estados Unidos, aprobada en 1791 con el objetivo de proteger la libertad de expresión, reunión y credo. La jurisprudencia marcada por el Tribunal Supremo ha servido para que la justicia estadounidense dictamine que los ciudadanos que emiten información y opiniones en Internet (conocidos genéricamente como blogueros), tienen los mismos derechos que los periodistas profesionales y no pueden ser acusados de difamación si no se prueba que han actuado con negligencia ${ }^{30}$.

Todas estas pautas indican que será periodista la persona que defienda la libertad de expresión a través de la emisión de mensajes veraces, ajustados a la realidad, con pluralidad de fuentes, sin estridencias o exageraciones vanas, sin más ánimo que el de hacer un trabajo útil para los ciudadanos y actuando con buena fe. Y será periodismo el producto que se elabore bajo estas premisas. La jurisprudencia no otorga demasiada importancia al hecho de que sea profesional o no quien lo haga.

\section{La protección de los periodistas no profesionales}

Uno de los beneficios que disfrutan los periodistas profesionales, es el derecho a no revelar sus fuentes de información. ¿Deben los ciudadanos disponer también de esta posibilidad? La Asamblea Parlamentaria del Consejo de Europa recomienda replantearse el asunto de la protección para mantener las fuentes en el anonimato:

"They (the media) use information and images originating from non-journalists to a larger extent. Non-journalists also publish their own or third-party information and images on their own or third-party Internet media, accessible to

${ }^{29}$ Supreme Court of The United States of America, No. 08-205. Citizens United, appellant v. Federal election commission on appeal from The United Stated District Court for the District of Columbia. 558 U. S. (2010), January 21, 2010, p. 36. https://www.law.cornell.edu/supct/pdf/08-205P.ZO

${ }^{30}$ Appeal from the United States District Court for the District of Oregon. 17 January 2014, p. 2. http://cdn.ca9.uscourts.gov/datastore/opinions/2014/01/17/12-35238.pdf 
a wide and often undefined audience. Under these circumstances, it is necessary to clarify the application of the right of journalists not to disclose their sources of information." 31

La UNESCO ${ }^{32}$ aboga por considerar a estos informadores improvisados de igual modo que a los periodistas profesionales. En el Plan de Acción de las Naciones Unidas Para la Seguridad de los Periodistas (2012) propone incluir a todos, por la defensa de los derechos humanos que llevan a cabo, y no limitar la posibilidad de reclamar protección judicial sólo a quienes formalmente son reconocidos como tales. En el mismo sentido se pronuncia el Relator Especial de la ONU para la libertad de expresión. No importa la formalidad de quién es o no periodista, porque lo relevante es que todas las personas que realicen esta actividad tengan idéntica protección, lo cual incluye a los ciudadanos mientras hagan el mismo trabajo:

\footnotetext{
"Such a definition of journalists includes all media workers and support staff, as well as community media workers and so-called citizen journalists when they momentarily play that role" 33 .
}

Llama la atención el uso de la expresión citizen journalists when they momentarily play that role pues parece que nos sitúa ante una posibilidad de protección de ida y vuelta, concepto similar a la teoría de la puerta giratoria que se aplica a la pérdida de la protección de las personas civiles cuando toman parte en acciones armadas y mientras dure esa participación ${ }^{34}$, y que mantiene un amplio debate sobre cuáles son los límites de esta categoría protegida y el peligro de que tales individuos recobren la inmunidad durante el lapso de tiempo entre dos actos de hostilidad ${ }^{35}$. Conviene recordar que un periodista, profesional o ciudadano, no trabaja a base de destellos temporales. Es cierto que a veces puede obtener un material de gran valor informativo por puro azar, pero la labor de recoger, contrastar, verificar, ordenar y difundir informaciones requiere algo más que momentos puntuales, y en situación de conflicto supone arriesgar la vida

31 Parliamentary Assembly, The Council of Europe. RECOMMENDATION 1950 (2011) The protection of journalists' sources. 25 January 2011. http://assembly.coe.int/Main.asp?link=/ Documents/AdoptedText/ta11/EREC1950.htm

32 The United Nations Plan of Action on the Safety of Journalists and the Issue of impunity, 27 March 2012. http://www.unesco.org/new/fileadmin/MULTIMEDIA/HQ/CI/CI/pdf/IPDC/ipdc28 dg_safety_report_final_rev.pdf

${ }^{33} \mathrm{~A} / \mathrm{HRC} / 20 / 17$, Informe del Relator especial sobre la promoción y protección del derecho a la libertad de opinión y expresión, Frank La Rue. (4 Junio 2012), párr. 4. http://www.ohchr.org/ Documents/HRBodies/HRCouncil/RegularSession/Session20/A-HRC-20-17_en.pdf

34 Artículo 51.3 del Protocolo Adicional 1 a los Convenios de Ginebra: "Las personas civiles gozarán de la protección que confiere esta Sección, salvo si participan directamente en las hostilidades y mientras dure tal participación."

35 Rodríguez-Villasante y Prieto, J.L., "La pérdida de la inmunidad de las personas civiles por su participación directa en las hostilidades, Cuadernos de estrategia Instituto Español de Estudios Estratégicos-Cruz Roja Española, núm. 160, enero 2013, p.195. http:/www.ieee.es/Galerias/fichero/ cuadernos/CE_160_La_respuesta_del_Derecho_Internacional.pdf 
misma por esta tarea. Con la inclusión de los periodistas ciudadanos en el debate de la protección, evoluciona notablemente la codificación de la función y categoría de los reporteros de guerra. Si nos remontamos al inicio, en 1975, el proyecto de Convención de las Naciones Unidas sobre la protección de los periodistas en misión peligrosa en zonas de conflicto armado, origen del artículo 79 del Protocolo Adicional 1 a los Convenios de Ginebra (1977), establecía que el término periodista sólo se podía aplicar : "a los corresponsales, reporteros, fotógrafos, camarógrafos y sus ayudantes técnicos de filmación, de radio y de televisión, que habitualmente

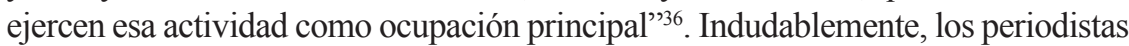
ciudadanos no ejercen esa labor como ocupación principal, así que nunca habrían gozado siquiera del beneficio de la duda en el siglo pasado. Pero si se rebaja la exigencia a una mera participación temporal se apuntala la importancia que tiene el hecho de informar por encima de quién suministre esa información. Y esta misma norma sigue el Comité de Derechos Humanos de la ONU, como ya hemos visto, cuando establece que el periodismo es una función compartida por distintos actores, lo que incluye a quienes no lo ejercen de manera profesional o remunerada ${ }^{37}$.

Lamentablemente, en demasiadas ocasiones los informadores continúan entregando sus vidas por hacer un trabajo periodístico sin importar que sean profesionales. La represión no distingue y a medida que su efecto ha ganado influencia en los medios de comunicación, también los ciudadanos se han equiparado a ellos no sólo por la relevancia de su trabajo, sino por la gravedad de los ataques que sufren ${ }^{38}$. En los nuevos conflictos armados la cuestión de la protección de los periodistas se abre a nuevos supuestos tras la incorporación de facto de los informadores no profesionales. Incluso hay ya asociaciones gremiales, como el Comité para la Protección de los Periodistas ${ }^{39}$, que piden protección para todos sin distinción y agrandan el círculo para incluir a los citizens, lo que parece un reconocimiento implícito de que su aportación es tan valiosa como las crónicas de los reporteros más expertos.

En definitiva, parece asentada la visión de que los ciudadanos pueden igualarse con los profesionales y gozar de la misma protección cuando afronten los mismos riesgos. En estos casos merecen la misma consideración jurídica, aunque bien es cierto que la dificultad radica precisamente en localizar qué ciudadanos están en peligro precisamente por el hecho de difundir mensajes y cuáles ${ }^{40}{ }^{40}$. Está claro que lo que convierte a una persona en potencial víctima

${ }^{36}$ Art. 2, (a) del proyecto de Convención de las Naciones Unidas sobre la protección de los periodistas en misión peligrosa en zonas de conflicto armado, 1 de agosto de 1975, documento ONU A/10147, Anexo I.

${ }^{37} \mathrm{CCPR} / \mathrm{C} / \mathrm{GC} / 34$ Comité de Derechos Humanos de la ONU, op. cit., nota 19.

38 UNESCO, op. cit. nota 4.

39 Comité para la Protección de los Periodistas (CPJ), Manual de seguridad para periodistas, https://cpj.org/security/guide_es.pdf

${ }^{40}$ Heyns, C., Srinivasan, S., "Protecting the right to life of journalists: The need of a higher level of engagement." Human Rights Quarterly, Vol. 35, 2013, n 2, p. 307.

Araucaria. Revista Iberoamericana de Filosofía, Política y Humanidades, año 18, n 36. Segundo semestre de 2016. Pp. 111-130. ISSN 1575-6823 e-ISSN 2340-2199 doi: 10.12795/araucaria.2016.i36.06 
no es el hecho de ser profesional sino la repercusión del material que difunde, lo cual le hace acreedor de una protección que no contempla el vigente Derecho Internacional Humanitario para que puedan continuar con una función que se ha demostrado útil.

\section{El valor del periodismo ciudadano en los conflictos armados actuales}

La conclusión provisional que cabe extraer de lo expuesto hasta el momento es que tanto si abordamos este fenómeno desde un punto de vista jurídico como periodístico, la realidad muestra que los ciudadanos pueden ayudar a la protección y difusión de los derechos fundamentales tanto como los reporteros más experimentados. Quizá el ejemplo más reciente sea la concesión por parte del Parlamento Europeo del premio Sajarov 2015 a la libertad de conciencia al bloguero saudí Raif Badawi, que cumple en la actualidad una condena de diez años de prisión por insultar al Islam en la web en la que promueve el debate social, político y religioso ${ }^{41}$. El Relator de la ONU para la libertad de expresión destaca la importancia de estas personas anónimas como proveedores de noticias en situaciones de guerra, así como el imprescindible papel que supone Internet para lograrlo, y coloca en las revueltas de la primavera árabe a partir de 2010, como antes hemos apuntado, el punto de inflexión que confirmó su validez:

\footnotetext{
"Internet puede servir como herramienta positiva para aumentar la transparencia en la conducta de los que detentan el poder, obtener acceso a las diversas fuentes de información, facilitar la participación activa de los ciudadanos en la construcción de las sociedades democráticas y luchar contra los regímenes autoritarios, como lo demuestra la primavera árabe"42.
}

En Egipto, durante la revuelta que derrocó al presidente Mubarak en 2011, varios grupos contrarios al régimen usaron la red de telefonía terrestre que no había sido interrumpida por las autoridades, para ofrecer desde el extranjero un canal de comunicación a la población. El servicio era lento y caro, pero Google y Twitter facilitaron un buzón de voz para que los ciudadanos pudieran dejar mensajes que luego eran traducidos en texto y difundidos por estas redes a todo el mundo ${ }^{43}$, sabedores del interés que despertaban estos testimonios. Ambas empresas ganaron una popularidad enorme, a la vez que convirtieron a

${ }^{41}$ European Parliament, Press Service 20 October 2005. http://www.europarl.europa.eu/pdfs/ news/public/story/20151023STO99024/20151023STO99024_en.pdf

${ }^{42}$ Asamblea General ONU A/66/290. Promoción y protección del derecho a la libertad de opinión y de expresión. 10 agosto 2011, párr. 12. http://www.un.org/es/comun/docs/index.asp?symbol=A\%2F $66 \% 2 \mathrm{~F} 290 \&$ Submit $=$ Buscar\&Lang $=\mathrm{S}$

${ }^{43}$ The Economist, "Reaching for the kill switch", 10 february 2011. http://www.economist.com/ node/ 18112043

Araucaria. Revista Iberoamericana de Filosofí, Política y Humanidades, año 18, $\mathrm{n}^{\circ} 36$. Segundo semestre de 2016. Pp. 111-130. ISSN 1575-6823 e-ISSN 2340-2199 doi: 10.12795/araucaria.2016.i36.06 
sus anónimos emisores en periodistas ciudadanos, consolidando el incipiente proceso. Y lo mismo que los profesionales, también los ciudadanos han sufrido represalias en forma de persecuciones y ataques deliberados tanto por parte de las fuerzas leales al régimen como por las facciones contrarias, que han visto en su labor un peligroso foco delator. En el caso de Egipto, el propio ex presidente Mubarak tuvo que responder por estos cargos entre otros ante el tribunal que le juzgó en 2015 tras su derrocamiento cuatro años antes.

En Libia, la guerra civil de 2011 duró apenas unos meses e igualmente puso fin al régimen de Muammar Gaddafi. También aquí la labor de los ciudadanos no profesionales fue determinante para transmitir la evolución del conflicto tanto dentro como fuera del país. La propia captura y ejecución del Coronel fue grabada con el teléfono móvil de uno de los rebeldes que participó en su linchamiento, y unos minutos después difundida a todo el mundo a través de Internet y gracias a las cabeceras de las principales empresas informativas internacionales, que no dudaron en publicarlas conscientes de su enorme valor periodístico.

Pero especialmente significativo fue el papel del ciudadano libio Mohammed Nabbous ${ }^{44}$, cuyo nombre y aportación están ligados al triunfo de la revuelta. Gracias a sus conocimientos informáticos fundó su propio canal en internet, Libia Alhurra, a través del que emitía reportajes elaborados con equipos domésticos. Pronto consiguió gran seguimiento en todo el mundo e incluso el canal árabe de televisión Al-Jazeera, se interesó por su trabajo y llegó a emitirlo considerándolo fuente objetiva y válida, otorgándole el mismo tratamiento que si lo hubiera elaborado un periodista profesional. Los vídeos de Nabbous tuvieron más repercusión que el trabajo de otros muchos corresponsales de larga experiencia destacados en Libia, lo que motivó la enemistad del régimen. El joven reportero murió en marzo de 2011 abatido por las tropas leales a Gaddafi en la ciudad de Bengasi mientras grababa material para una nueva entrega. No pudo asistir al triunfo de la revolución, pero su legado ayudó a conseguirlo y desde entonces se ha convertido en un icono para esta categoría emergente de periodistas ciudadanos.

En Siria, similar protagonismo e idéntico final corrieron Ferzat Jarban y Basil al-Sayed, quienes después de documentar las atrocidades cometidas en el transcurso de la guerra civil, murieron víctimas de un ataque premeditado por parte de las fuerzas leales al gobierno ${ }^{45}$.

Libia, Egipto, Siria, Arabia Saudí... no son los únicos casos, pero sí quizá los más notorios hasta el momento, en un paradigma muchas veces repetido donde, mientras las autoridades dificultan el acceso a los periodistas

${ }^{44}$ http://www.periodismociudadano.com/2011/03/20/muere-por-disparos-mohammed-nabboussimbolo-del-periodismo-ciudadano-en-la-crisis-libia/

${ }^{45}$ Committee to Protect Journalists, Journalists Security Guide, p. 5 https://cpj.org/security/guide.pdf 
profesionales, los ciudadanos suplen su ausencia reuniendo información y colocándola en Internet (a través de blogs independientes o de las llamadas redes sociales). Su trabajo ha abierto ventanas a través de las cuales el resto del mundo puede ver los conflictos, conocer el drama de las víctimas o las violaciones del Derecho Internacional Humanitario. Además, ha puesto fin al esquema clásico de la información unidireccional en la que el emisor y el receptor siempre ocupan los mismos papeles; ahora se intercambian. Con la participación ciudadana en los flujos de información a través de Internet el molde se ha roto para siempre.

\section{El periodismo ciudadano como fenómeno organizado}

¿Está amenazado el periodismo profesional? Con el impacto de las nuevas tecnologías y la irrupción del fenómeno ciudadano, cuyos últimos efectos aún no conocemos, ¿qué parcela seguirá ocupando la información convencional? Si buena parte de las noticias más destacadas en los últimos conflictos armados las hemos conocido gracias a los periodistas anónimos, resulta lógico preguntarnos qué función tienen los profesionales.

Hay quien sostiene que los primeros solo tienen valor cuando los segundos no están cerca de la noticia pues existe el riesgo de que la no profesionalidad distorsione los hechos, aún involuntariamente ${ }^{46}$. Es cierto que la información necesita un contexto y un manejo adecuados para ser útil e inteligible, es preciso situarla en sus antecedentes y presentarla de manera ordenada, y estas habilidades se le presuponen al periodista formado. Pero el informador espontáneo también ha demostrado en muchas ocasiones su capacidad y adecuación, cumpliendo el objetivo esencial que se exige a un periodista, que es básicamente informar. Nadie duda de que las condiciones de trabajo y el ámbito general en el que actualmente se desarrolla el periodismo han cambiado, pero su función social permanece inalterable con el paso de los años, es decir, llevar a la población mensajes útiles, asentados en la veracidad y con el único objeto de informar de buena fe, como sentenció el TEDH según se ha visto. Siempre que cumpla estas pautas no habría que mirarlo como una amenaza para el periodismo profesional, sino como un complemento, una fuente más de información potencialmente tan válida como las convencionales, especialmente en los lugares donde no hay profesionales, como en los llamados conflictos olvidados, que no despiertan el interés de las grandes empresas de comunicación a pesar de arrojar gran número de víctimas inocentes. Aquí, los ciudadanos se han convertido en únicos valedores del derecho que tienen a que el mundo conozca su situación. Sin embargo, en los lugares donde profesionales y ciudadanos coinciden, es difícil

${ }^{46}$ Taylor, P., "Journalists under fire: The reporting of war and international crisis" En: News, public relations and power. London, Simon Cottle, 2003.

Araucaria. Revista Iberoamericana de Filosofia, Política y Humanidades, año 18, no 36. Segundo semestre de 2016. Pp. 111-130. ISSN 1575-6823 e-ISSN 2340-2199 doi: 10.12795/araucaria.2016.i36.06 
matizar entre el trabajo de ambos y ya hay propuestas para llamar a quienes emitan información "proveedores de noticias", un término más general y comprehensivo, que elimina distinciones, para incluir a todas las personas que trabajan en los medios de comunicación, así como a los ciudadanos, siempre que éstos actúen con criterio periodístico profesional ${ }^{47}$.

¿Cuál es el siguiente paso? ¿Es necesario organizar un fenómeno que nació de manera espontánea, o es la ausencia de jerarquías lo que le hace ser útil? El periodismo ciudadano organizado, se está desarrollando especialmente en el Reino Unido aunque en todo el mundo aparecen cada vez más experiencias similares. En España, la web periodismociudadano.com ha llevado la iniciativa de otorgar a la ciudadanía los medios para difundir sus mensajes. Si bien sus creadores declaran que los particulares anónimos deben tomar posición activa para controlar (y en su caso contrarrestar) el efecto de los medios de comunicación convencionales, todos son periodistas o tienen relación con el periodismo profesional. Animan a la participación colectiva, a tomar conciencia de su potencial y a ejercerlo de manera organizada:

"La antigua audiencia pasiva ahora es activa: los usuarios se pueden informar unos a otros, tanto a nivel global como en los ámbitos más locales, haciendo un uso intensivo de las herramientas tecnológicas que tienen a su alcance, a través del gran canal de distribución que es Internet. Esta es una de las razones por las que los ciudadanos, implicados en tareas informativas que se han convertido en el quinto poder, en los vigilantes del cuarto poder" ${ }^{\prime 4}$.

Iniciativas como Freedomfone ${ }^{49}$, la red para la intercomunicación de usuarios de zonas en desarrollo o en riesgo de exclusión, pensada para el intercambio de noticias, pretenden abrir un nuevo camino para la ordenación de la comunidad no profesional. Con la misma intención nació Spot.us ${ }^{50}$, un proyecto cuyos autores defienden como una nueva manera de enfocar el periodismo como un proceso y no como un objeto. Proponen esta herramienta para favorecer la incorporación de la sociedad organizada a las redes de la comunicación global, lo que según sus creadores sería beneficioso para todos pues el periodismo ha transcurrido históricamente tras puertas cerradas y ha involucrado solo a las personas de la propia industria ${ }^{51}$. En el ámbito de los conflictos armados, instituciones como el

${ }^{47}$ Burri, N., Bravery or Bravado? The prosecution of news providers in armed conflicts, LeidenBoston, ed. Brill Nijhoff, 2015 (p.115)

48 Espiritusanto, O., Gonzalo Roríguez, P., Periodismo ciudadano: Evolución positiva de la comunicación. Barcelona, Ed. Ariel, 2011. http://www.fundacion.telefonica.com/es/que_hacemos/ media/publicaciones/Periodismo_ciudadano.pdf

49 www.freedomfone.org

${ }^{50}$ http://www.spot.us/

${ }^{51}$ Cohn, D., "Periodismo ciudadano, investigación". En Espiritusanto, O., Gonzalo Roríguez, P., op. cit. nota 48 , p. 82. http://www.fundacion.telefonica.com/es/que_hacemos/media/publicaciones/ Periodismo_ciudadano.pdf

Araucaria. Revista Iberoamericana de Filosofía, Política y Humanidades, año 18, n 36 . Segundo semestre de 2016. Pp. 111-130. ISSN 1575-6823 e-ISSN 2340-2199 doi: 10.12795/araucaria.2016.i36.06 
Instituto para la información sobre la Guerra y la $\mathrm{Paz}^{52}$ (IWPR, por sus siglas en inglés), con sedes en Londres, Países Bajos y Estados Unidos, supone hoy día una de las principales ONG que promueve el periodismo no profesional en más de 30 países en conflicto, ayudando a la población local a transmitir la crisis a todo el mundo, para lograr la atención desde el exterior que derive en la pacificación y posterior buena gobernanza.

Por su parte, los medios de información convencionales son muy conscientes de la urgencia de reafirmar su misión y estar en condiciones de responder a las expectativas de públicos versátiles. Rupert Murdoch -accionista principal News Corporation, uno de los grupos de comunicación más importantes del mundo- ya avisó de que los jóvenes no quieren depender del periódico matutino para mantenerse informados, ni admiten una figura divina que les diga, desde arriba, qué es importante. Tal es el efecto de este cambio generacional en el modo de consumir la información que hasta la $B B C$ consideró formar a los ciudadanos para que hicieran mejor su trabajo informativo, tras comprobar la extraordinaria difusión y valía de sus aportaciones ${ }^{53}$. La cadena británica ha lanzado iniciativas para ofrecer capacitación en periodismo y redes sociales a miembros de comunidades locales, al tiempo que en la página web de su Escuela de Periodismo publica recursos para los aspirantes a periodistas ciudadanos. En España el diario El País inauguraba en 2007 la sección "Yo periodista digital", animando a cualquiera que tenga una noticia a difundirla a través de la web de esta cabecera ${ }^{54}$.

Pero tras la organización de un fenómeno que nació desorganizado y libre de control alguno puede esconderse un intento de limitarlo. El periodismo ciudadano supone una nueva aportación al mundo de la comunicación básicamente a través de Internet, un espacio virtual y saturado de mensajes. Las redes sociales se integran cada vez más en nuestra cultura y en un período de tiempo muy breve y reciente nos hemos acostumbrado a utilizarlas como fuentes válidas de información. Sin embargo, distinguir su procedencia es muy importante porque en ocasiones somos víctimas sin saberlo de una estrategia premeditada ${ }^{55}$.

\footnotetext{
${ }^{52}$ Institute for War and Peace Reporting https://iwpr.net/

${ }^{53}$ Huguenin-Benjamin, R., “¿La comunicación pública puede proteger a las víctimas?” Revista internacional de la Cruz Roja. http://www.icrc.org/Web/spa/sitespa0.nsf/htmlall/6QAMYE?OpenD ocument\&style=custo print

${ }^{54}$ El País, 18 abril 2007. http://elpais.com/diario/2007/04/18/sociedad/1176847209_850215.html

${ }_{55}$ VV.AA. Measuring the Tweeting Behavior of Propagandists http://www.cs.umd.edu/ lume/ files/icwsm12.pdf
} 


\section{Conclusiones}

El debate sobre periodismo ciudadano o periodismo profesional abre nuevas interrogantes que se tenían por resueltas años atrás, pero como sucede en otros muchos órdenes del universo jurídico internacional, cuando teníamos las respuestas, el siglo XXI cambió las preguntas. ¿Qué es periodismo? ¿Quién es periodista?

La revolución digital y el acceso que tienen los ciudadanos a la esfera global gracias a Internet, ha impulsado el desarrollo de los Derechos Humanos, especialmente los relacionados con la libertad de expresión, y ha modificado el esquema convencional de transmisión de información, incluyendo a cualquier persona con capacidad técnica para hacerlo. El nuevo escenario también pone al descubierto el ansia de los gobiernos por dominarlo y afina las técnicas de propaganda. Las grandes compañías de noticias se ven obligadas a compartir protagonismo, ayudando a la difusión de material que suministran personas anónimas, sin formación o experiencia, pero de indiscutible valor. El fenómeno de los periodistas ciudadanos no parece tener vuelta atrás, ni siquiera es previsible cuál será el paso siguiente, inmerso como está en un proceso inabarcable e incierto, que debe servir para afianzar la libertad de expresión y del derecho que tenemos todas las personas a emitir o recibir una información libre y plural, como recogen la Declaración Universal de los Derechos Humanos y el Pacto Internacional de Derechos Civiles y Políticos. En este sentido, la imprevisibilidad que rige al periodismo ciudadano es un aval que afianza su utilidad.

Independientemente de la denominación, y al margen de los argumentos jurídicos expuestos, lo cierto es que en un conflicto armado un ciudadano anónimo puede convertirse en el informador más eficaz y pasar en sólo un momento de ser un civil sin relación directa con el conflicto, a sufrir los ataques de una de las partes por la publicación que acaba de hacer, y por lo tanto tendrá la misma necesidad de protección que los corresponsales que trabajan para las empresas informativas. Ambos realizan la misma función y afrontan los mismos riesgos. Comparten más semejanzas que diferencias, lo que obliga a abrir el debate sobre si todos deben estar incluidos en la misma categoría. En realidad ya lo están, pues los periodistas profesionales son a todos los efectos personas civiles y no gozan de más garantías para su seguridad que ésta, lo que atendiendo a la alta siniestralidad que sufren equivale a decir ninguna. Pero se hace necesaria una revisión de la protección de quien ejerza el periodismo porque es esta labor la que les hace afrontar un peligro mayor al resto de civiles, sin importar que sean profesionales o no. Los tribunales de justicia ya han hablado sobre la irrelevancia de distinguir a unos y a otros, porque lo esencial es el producto que ofrecen. Básicamente, da igual quién elabore el mensaje si el resultado final redunda en amenazas para su persona, o ayuda al fortalecimiento de la libertad de expresión. $\mathrm{Y}$ dado que los profesionales trabajan para empresas con intereses muy concretos (comerciales o políticos) la labor anónima, por altruista y desinteresada, supone una garantía adicional para la información libre. 


\section{Referencias bibliográficas:}

Burri, N., Bravery or Bravado? The prosecution of news providers in armed conflicts, Leiden-Boston, Ed. Brill Nijhoff, 2015.

Bustos Gilbert, R., "Los derechos de libre comunicación en una sociedad democrática" en VV.AA, La Europa de los derechos. El convenio europeo de Derechos Humanos. Madrid, Centro de Estudios Políticos y Constitucionales, 2014.

Cohn, D., "Periodismo ciudadano, investigación". En Espiritusanto, O., Gonzalo, P., Periodismociudadano: Evolución positiva de la comunicación. Barcelona, Ed. Ariel, 2011. http://www.fundacion.telefonica.com/es/que hacemos/media/publicaciones/Periodismo_ciudadano.pdf

Heyns, C., Srinivasan, S., "Protecting the right to life of journalists: The need of a higher level of engagement." Human Rights Quarterly, Vol. 35, 2013, n 2 .

Huguenin-Benjamin, R., “¿La comunicación pública puede proteger a las víctimas?" Revista internacional de la Cruz Roja, n. 860, Diciembre de 2005. http://www.icrc.org/Web/spa/sitespa0.nsf/htmlall/6QAMYE?Open Document\&style=custo_print

Kapuscinski, R., Los cínicos no sirven para este oficio: Sobre el buen periodismo, Barcelona, Ed. Anagrama, 2007.

Rodríguez-Villasante y Prieto, J.L., "La pérdida de la inmunidad de las personas civiles por su participación directa en las hostilidades, Cuadernos de estrategia Instituto Español de Estudios Estratégicos-Cruz Roja Española, núm. 160, Enero 2013. http://www.ieee.es/Galerias/fichero/cuadernos/ CE_160_La_respuesta_del_Derecho_Internacional.pdf

Taylor, P., "Journalists under fire: The reporting of war and international crisis" en: News, public relations and power, London, Simon Cottle, 2003.

\section{Sentencias y pronunciamientos judiciales:}

Appeal from the United States District Court for the District of Oregon. January 17, 2014, p. 2. http://cdn.ca9.uscourts.gov/datastore/ opinions/2014/01/17/12-35238.pdf

CORTE INTERAMERICANA DE DERECHOS HUMANOS: Setencia caso Herrera Ulloa c. Costa Rica. 2 julio 2004. http://www. corteidh.or.cr/docs/casos/articulos/seriec_107_esp.pdf Sentencia caso Kimel Vs. Argentina, 2 de Mayo de 2008. http://www.corteidh.or.cr/docs/ casos/articulos/seriec_177_esp.pdf Sentencia caso Mémoli Vs. Argentina. Excepciones Preliminares, Fondo, Reparaciones y Costas. 22 de Agosto 
de 2013. Serie C No. 265 http://www.corteidh.or.cr/docs/casos/articulos/ seriec_265_esp.pdf

Case of Goodwin v. The United Kingdom. March 27, 1997. http://hudoc.echr. coe.int/sites/eng/pages/search.aspx?i=001-57974 http://www.coe.int/t/ dghl/standardsetting/media/doc/cm/rec(1996)004_EN.asp

Judgment Bladet Tromso and Stensaas v. Norway. May 20, 1999. http://hudoc. echr.coe.int/eng\#\{“fulltext":["Fressoz"],"appno":[“21980/93"],"item

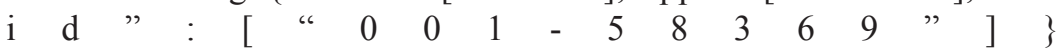
Judgment Novaya Gazeta v. Rusia. March 28, 2013. http://hudoc.echr.coe. $\mathrm{int} /$ sites/eng/pages/search.aspx?i=001-117683

International Criminal Tribunal for the Former Yugoslavia. Decision on prosecution's second request for a subponea of Jonathan Randal. 29 Junio 2003. http://www.icty.org/x/cases/brdanin/tdec/en/030630.htm

Suprema Corte de Justicia de la Nación. México, Septiembre 2012. http://www.

bjdh.org.mx/interamericano/doc_JP_CADH?documento=2001677.pdf

Supreme Court of The United States of America, No. 08-205. Citizens United, appellant v. Federal election commission on appeal from The United Stated District Court for the District of Columbia. 558 U. S. (2010), January 21, 2010, p. 36. https://www.law.cornell.edu/supct/pdf/08-205P.ZO

\section{Organizaciones internacionales:}

Asamblea General de la ONU, A/RES/68/163 (21 Febrero 2014). http://www.un.org/en/ga/search/view_doc.asp?symbol=A/ RES/68/163\&referer=http://www.un.org/en/events/journalists/\&Lang=S

Asamblea General ONU A/66/290. Promoción y protección del derecho a la libertad de opinión y de expresión (10 Agosto 2011). http://www.un.org/ es/comun/docs/index.asp?symbol=A\%2F66\%2F290\&Submit=Buscar\&L ang $=\mathrm{S}$

Comité de Derechos Humanos de la ONU, Observación General número 34, CCPR/C/GC/34 (12 Septiembre 2011) http://www.un.org/es/comun/ docs/index.asp?symbol=CCPR/C/GC/34\&referer=http:/ /www.un.org/es/ $\mathrm{ga} /$ documents/symbol.shtml\&Lang $=\mathrm{E}$

Council of Europe, Parliamentary Assembly, Recommendation 1950 (2011) The protection of journalists' sources. January 25, 2011. http://assembly. coe.int/Main.asp?link=/Documents/AdoptedText/ta11/EREC1950.htm

Council of Europe, Recommendation No. R (96) 4 of the Committee of Ministers to Members States on the Protection of Journalists in situation of Conflicts and Tensions (Adopted by the Committee of Ministers on 3 May 1996 at its $98^{\text {th }}$ Session). 
Informe del Relator Especial de la ONU sobre la promoción y protección del derecho a la libertad de opinión y expresión, Frank La Rue. A/65/284 (11 Agosto 2010). http://www.acnur.org/t3/fileadmin/Documentos/ BDL/2011/7497.pdf?view=1 http:// daccess-dds-ny.un.org/doc/ UNDOC/GEN/N10/482/88/PDF/N1048288.pdf?OpenElement

Informe del Relator especial sobre la promoción y protección del derecho a la libertad de opinión y expresión, Frank La Rue. A/HRC/20/17 (4 Junio 2012). http://www.ohchr.org/Documents/HRBodies/HRCouncil/ RegularSession/Session20/A-HRC-20-17_en.pdf

International Telecommunication Union. Key ICT indicators for developed and developing countries and the world, totals and penetration rates (2015) http://www.itu.int/en/ITU-D/Statistics/Pages/stat/default.aspx

UNESCO, Tendencias Mundiales en Libertad de Expresión y Desarrollo de los Medios (2014). Accesible en: http://unesdoc.unesco.org/ images/0022/002297/229704S.pdf

UNESCO. The United Nations Plan of Action on the Safety of Journalists and the Issue of impunity. March 27, 2012. http://www.unesco.org/ new/fileadmin/MULTIMEDIA/HQ/CI/CI/pdf/IPDC/ipdc28_dg_safety_ report_final_rev.pdf

\section{Organizaciones profesionales de periodistas:}

Committee to Protect Journalists, http://www.cpj.org/security/2012/05/dontget-your-sources-in-syria-killed.php

Committee to Protect Journalists, Journalists Security Guide, https://cpj.org/ security/guide.pdf

Reporters Without Borders, World press freedom index 2015 http://index.rsf. org/\#!/ 